\title{
Um estudo global sobre as questões de gênero no jornalismo
}

DOI: https://doi.org/10.1590/1809-58442020313

\author{
Ricardo Henrique Almeida Dias ${ }^{1}$ \\ https://orcid.org/0000-0002-0085-1919 \\ ${ }^{1}$ (Escola de Línguas Ocidentais, Universidade de Estudos Internacionais de Jilin, Departamento de Português. \\ Changchun - China).
}

CARTER, C.; STEINER, L.; ALLAN, S. Journalism, gender, and power. London and New York: Routledge, 2019.

A relevância dos estudos de gênero no âmbito das pesquisas em comunicação pôde ser reafirmada com a realização do $41^{\circ}$ congresso nacional da Sociedade Brasileira de Estudos Interdisciplinares da Comunicação, a Intercom, em Joinville, 2018. Com o tema "Desigualdades, gêneros e comunicação", o evento reuniu diversos pesquisadores, professores, estudantes de graduação e pós-graduação para discutir o assunto. Uma das obras que pode servir de referência aos estudos desse tema está no recente trabalho publicado pelas professoras Cynthia Carter e Linda Steiner e o professor Stuart Allan. Stuart e Cynthia, que estão na Universidade de Cardiff, já haviam, em conjunto com Gill Branston em 1998, editado o livro "News, gender and power" (1998), que trouxe diversos trabalhos sobre as questões de gênero e jornalismo. Por diversas vezes,

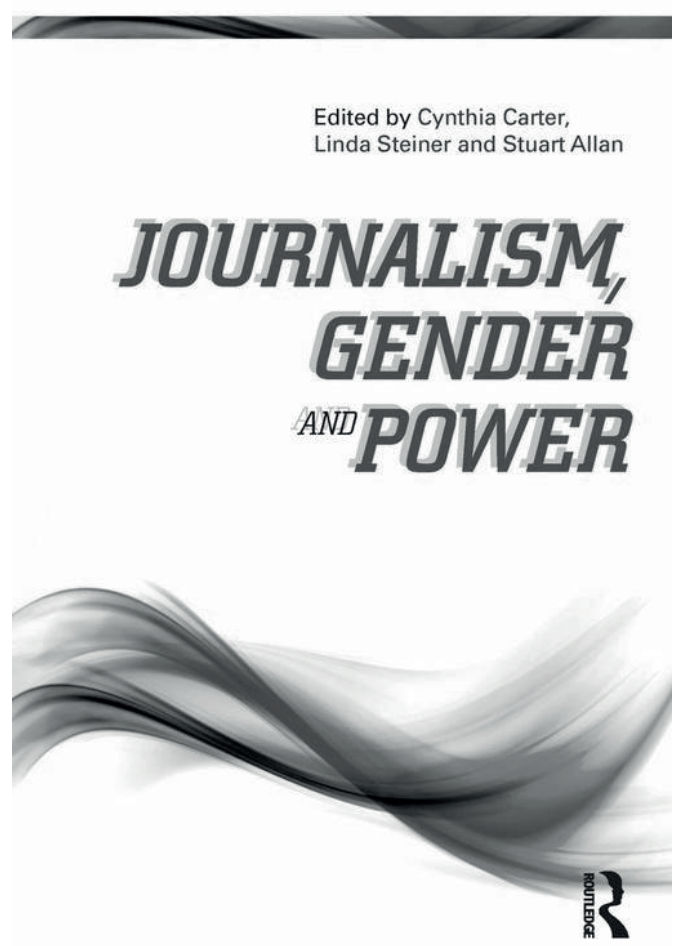
os autores estabelecem uma comparação de como os problemas sobre as questões de gênero evoluíram desde o lançamento do primeiro livro com o que está sendo lançado agora, o "Journalism, gender and power” (2019). Assim como o primeiro estudo, este conta com capítulos escritos por vários autores baseados em diversos países. Por isso, o livro é tão relevante por trazer pesquisas sobre as questões de gênero no jornalismo a partir do ponto de vista de culturas distintas. Outro ponto importante da obra é pelo seu objetivo em revisitar as propostas de elaboração e investigação de vários 
temas já tratados no livro anterior, estabelecendo uma comparação de duas décadas sobre as questões de gênero no jornalismo.

De acordo com a apresentação dos editores, as últimas duas décadas, período de tempo de publicação entre os dois livros, têm testemunhado um significativo avanço no cotidiano das mulheres no jornalismo ao redor do mundo, com suas carreiras e muitas realizações. Os editores lembram também que o número de mulheres escolhendo ser jornalistas nunca esteve tão alto, sendo que muitas delas estão determinadas a superar qualquer sexismo e racismo institucionalizado que apareçam em seus caminhos.

Entretanto, os editores fazem a ressalva que esse impulso para o progresso na igualdade de gêneros permanece um teste de resiliência, com muito trabalho a ser feito. Poucas organizações midiáticas garantem às mulheres igualdade com as suas contrapartes masculinas nos papéis de decisão editorial, função que faz a diferença quando se pensa em abordagens distintas do tradicional no processo de recolha, apresentação e interpretação das notícias. Similarmente, as jornalistas também frequentemente sofrem pela desigualdade nos salários, com padrões persistentes de discriminação sexista, mostrando o quanto é difícil alterar esses padrões.

Já com relação a cobertura midiática de questões de gênero, os editores lembram que no final dos anos 1990, muitos dos tópicos que eram recorrentemente ignorados, banalizados ou marginalizados, agora, rotineiramente apresentam uma base regular na paisagem midiática. No livro, podemos perceber que ainda existem sérios problemas que continuam a restringir muito essa cobertura, mas não se pode negar que não há atenção jornalística a essas questões globais. Exemplos incluem violência baseada em gênero, casamentos forçados, mutilações genitais femininas, acesso das meninas a educação, oportunidades de emprego, salários, direitos reprodutivos e a saúde das mães. Questões sensíveis em matéria de gênero, tais como a objetificação das mulheres ou a naturalização de uma hierarquia heteronormativa têm se tornado tópicos mais comuns se comparados com duas décadas atrás. Pesquisadores estão mostrando que há melhorias importantes, enquanto, ao mesmo tempo, reconhecem como a dinâmica do poder de gênero molda a cultura das redações, frequentemente via normas, valores e crenças consideradas tácitas. Mesmo aqueles jornalistas que alertam os seus leitores, ouvintes e telespectadores para os exemplos de sexismo na vida pública, às vezes parecem relutantes em estender essas críticas às suas próprias empresas midiáticas.

Do ponto de vista da pesquisa acadêmica, os editores compreendem que as pesquisas de gênero devem mostrar como e por que as questões de gênero são relevantes para o jornalismo nas culturas democráticas. Problemas de pesquisa do livro anterior, escrito em 1998, incluíam questões de autoria e controle das notícias pelos homens, no que os autores chamaram de "malestream" ou tendência masculina. Assim como outros temas, tais como empregabilidade das mulheres e discriminação na cultura das notícias, a imparcialidade e objetividade no contexto das questões de gênero, identidade profissional das jornalistas, a cobertura da violência sexual, a sexualização da mulher dentro das representações das notícias, a experiência cotidiana dos vieses de gênero, preconceito nas redações e as expectativas 
das audiências sobre as questões de gênero. Esses assuntos vistos do ponto de vista de hoje fazem com que cada um deles pareça diferente, ainda mantendo um ponto de partida para investigações preocupadas em reimaginar o jornalismo dentro do interesse público.

Os editores afirmam, também, que a extensão na qual as vozes das mulheres são incluídas nas notícias, tanto como produtoras de notícias, com as funções de repórteres e apresentadoras, quanto também como fontes, tem sido um ponto central de interesse no jornalismo nos últimos 20 anos. Melhorias nessas duas frentes têm se materializado de maneira muito devagar. Além dessa morosidade, os avanços têm sido desiguais entre os países e, surpreendentemente, em algumas plataformas de notícias as mulheres jornalistas perderam terreno em lugares anteriormente conquistados e seus números têm caído. Ainda permanecem desafios em áreas tais como o tratamento das mulheres jornalistas pelas suas fontes, bem como dentro de suas próprias organizações midiáticas, nas quais pode-se verificar por meio das contratações, promoções e salários. Alguns pesquisadores temem que os avanços nessas frentes têm começado a estagnar em muitas partes do mundo.

Os editores lembram de casos para exemplificar esses problemas. Com relação aos salários, houve o caso das jornalistas da edição britânica de Financial Times que ameaçaram entrar em greve em 2017 depois de descobrirem que os homens ganhavam 13\% a mais em média. O sindicato afirmou que faltava consciência por parte dos gestores, denunciando que havia também uma falta de transparência entre os pagamentos dos executivos.

Também atraindo manchetes, foram os casos envolvendo quatro editores estrangeiros da $B B C$. Eram duas mulheres e dois homens na função, sendo que as duas mulheres empregadas nessa mesma função ganhavam a metade que suas contrapartes masculinas. De acordo com Carrie Gracie, editora responsável pela China, isso evidencia como a $B B C$ perpetuava uma cultura secreta e ilegal de pagamentos. Do ponto de vista da estabilidade do trabalho de forma global, as mulheres jornalistas estão mais sujeitas a ser parte de um precário mercado de jornalistas freelancers, o que tem resultado na fragmentação do mercado e a consolidação dessa prática na cultura midiática.

Outra questão de gênero no jornalismo lembrada pelos editores está na denúncia de violência sexual. Durante um discurso para receber o prêmio pela reportagem que alegou a falta de conduta sexual do então âncora da CBS News, Charlie Rose, a jornalista do Washington Post Irin Carmon alertou que histórias de abuso na indústria das notícias são ainda suprimidas e que o problema é do sistema de privilégios que os homens usam para matar os casos. Logo após esse evento, vieram revelações explosivas de mulheres ao redor do mundo que, publicamente, trouxeram suas experiências de violência sexual como parte da campanha \#MeToo, que tem sido largamente coberta pelas notícias mundiais. Esses recentes eventos marcam uma potencial virada na cobertura jornalística sobre as violências sexuais em todo o mundo e as discussões mais amplas sobre igualdade de gêneros na sociedade.

A obra traz, também, diversas estatísticas sobre as mulheres no jornalismo em seus 24 capítulos. Suas 388 páginas são divididas em quatro partes: 1) As políticas de gênero na produção das notícias; 2) Novos discursos, sexualização e violência sexual; 3) Engendrando 
novas audiências e ativismo; e 4) Políticas e identidades nas notícias. O livro conta com um índice remissivo bem completo, o que pode facilitar a consulta a determinado assunto. Pela sua abrangência, a obra se constitui em uma leitura obrigatória a todos os pesquisadores, professores e estudantes sobre as questões de gênero na comunicação.

\section{Referências}

CARTer, C.; BRAnston, G.; Allan, S. News, Gender, and Power. London and New York: Routledge, 1998.

CARTER, C.; STEINER, L.; ALLAN, S. Journalism, gender, and power. London and New York: Routledge, 2019.

\section{Ricardo Henrique Almeida Dias}

Mestre e Doutor em Educação pela Faculdade de Educação da Universidade Estadual de Campinas (2015). Bacharel em Comunicação Social pela Universidade Federal de Mato Grosso do Sul (2006). Atualmente, é docente da Universidade de Estudos Internacionais de Jilin, Changchun - China. E-mail: ricardohadias@gmail.com.

Recebida em: 08.09.2019

Aprovada em: 09.09.2020

Este artigo é publicado em acesso aberto (Open Access) sob a licença Creative Commons Attribution Non-Commercial (CC-BY-NC), que permite uso, distribuição e reprodução em qualquer meio, sem restrições, desde que sem fins comerciais e que o trabalho original seja corretamente citado. 